\title{
Bor karbür tozu üretiminde farklı karbon kaynaklarının faz oluşumu ve mikroyapı üzerindeki etkisi
}

\author{
Kamil Kiraz ${ }^{1}$, Özge Balcı ${ }^{2 \star}$, Özge Çoşut ${ }^{3}$, Tuğhan Akbaşak ${ }^{4}$, Buğra Çiçek ${ }^{5}$, Mehmet Somer ${ }^{6}$ \\ ${ }^{1}$ Koç Üniversitesi Akkim Bor Tabanlı Malzemeler ve İleri Teknoloji Kimyasallar Uygulama ve Araştırma Merkezi, Rumelifeneri Yolu, \\ Sarıyer, İstanbul, Türkiye, ORCID ID orcid.org/0000-0001-7377-0047 \\ ${ }^{2}$ Koç Üniversitesi, Akkim Bor Tabanlı Malzemeler ve İleri Teknoloji Kimyasallar Uygulama ve Araştırma Merkezi, \\ Rumelifeneri Yolu, Sarıyer, İstanbul, Türkiye, ORCID ID orcid.org/0000-0001-6756-3180 \\ ${ }^{3}$ Koç Üniversitesi Akkim Bor Tabanlı Malzemeler ve İleri Teknoloji Kimyasallar Uygulama ve Araştırma Merkezi, Rumelifeneri Yolu, \\ Sarıyer, İstanbul, Türkiye, ORCID ID orcid.org/0000-0002-8277-9729 \\ ${ }^{4}$ Ak-Kim Kimya San. ve Tic. A.Ş., Çiftlikköy, Yalova, Türkiye, ORCID ID orcid.org/0000-0002-2916-2703 \\ ${ }^{5}$ Yıldız Teknik Üniversitesi, Metalurji ve Malzeme Mühendisliği Bölümü, Koç Üniversitesi Akkim Bor Tabanlı Malzemeler ve İleri Teknoloji \\ Kimyasallar Uygulama ve Araştırma Merkezi, İstanbul, Türkiye, ORCID ID orcid.org/0000-0001-8195-4153 \\ ${ }^{6}$ Koç Üniversitesi, Akkim Bor Tabanlı Malzemeler ve İleri Teknoloji Kimyasallar Uygulama ve Araştırma Merkezi, \\ Rumelifeneri Yolu, Sarıyer, İstanbul, Türkiye, ORCID ID orcid.org/0000-0001-5606-9101
}

\section{MAKALE BÍLGISi}

Makale geçmişi:

İlk gönderi 04 Ekim 2018

Revize gönderi 02 Ocak 2019

Kabul 13 Mart 2019

Online 30 Haziran 2019

Araştırma Makalesi

DOI: $10.30728 /$ boron.467351

Anahtar kelimeler:

Bor karbür,

Bor oksit,

Grafit,

Aktif karbon,

Mikroyapı

\begin{abstract}
ÖZET
Bu çalışmada, bor oksit ve farklı karbon kaynaklarından hareketle karbotermik yöntemle bor karbür tozu üretimi amaçlanmıştır. Hammadde olarak, $\mathrm{B}_{2} \mathrm{O}_{3}$ ve grafit ya da aktif karbon kullanılmış olup, toz karışımları bilyalı değirmende mekanik olarak aktive edilmiştir. Mekanik olarak aktive edilen tozlar, hidrolik preste peletler haline getirilmiş ve $\mathrm{Ar}$ atmosferi altında $1450^{\circ} \mathrm{C}$ 'de reaksiyona tabi tutulmuştur. Öğütme süresi/hızı, reaksiyon süresi, başlangıç toz miktarları ve farklı karbon kaynaklarının son ürün verimi ve faz yapısı üzerindeki etkisi incelenmiştir. Elde edilen toz ürünlerin karakterizasyonu, XRD, SEM ve organik element analizi yöntemleri ile gerçekleştirilmiştir. Öğütme ve presleme işlemleri sayesinde, son ürün yapısındaki kalıntı karbon miktarı önemli ölçüde azaltılmış ve teorik oluşum sıcaklığı $1360^{\circ} \mathrm{C}$ 'ye kadar düşürülmüştür. Optimum koşullarda elde edilen tozlar, yapısında en fazla \% 4 kalıntı karbon içeren ve ortalama $10 \mu \mathrm{m}$ partikül boyutuna sahip bor karbür tozlarıdır.
\end{abstract}

\section{The effect of different carbon sources on the phase formation and microstructure of boron carbide powders}

\section{ARTICLE INFO}

\section{Article history:}

Received 04 October 2018

Revised form 02 January 2019

Accepted 13 March 2019

Available online 30 June 2019

Research Article

DOI: $10.30728 /$ boron.467351

\section{Keywords:}

Boron carbide,

Boron oxide,

Graphite,

Activated carbon,

Microstructure

\begin{abstract}
The objective of this study is to synthesize boron carbide powders starting with boron oxide $\left(\mathrm{B}_{2} \mathrm{O}_{3}\right)$ and varying carbon sources such as graphite and activated carbon by using carbothermal method. Powder mixtures are mechanically activated with ball mill, pelletized in cold hydraulic press and reacted under Argon atmosphere at $1450^{\circ} \mathrm{C}$. Milling speed and time; reaction duration; varying carbon source and the ratio of the starting materials are experimented to observe the results upon the phase structure and the yield of the $\mathrm{B}_{4} \mathrm{C}$. The product characterization is carried out via XRD, SEM, particle size analyzer and organic elemental analysis methods. Mechanical pretreatment significantly reduces the amount of the unreacted carbon and lowers the theoretical reaction temperature down to $1360^{\circ} \mathrm{C}$. Under the optimum conditions, the yield contains $4 \%$ remaining carbon and approximately $10 \mu \mathrm{m}$ boron carbide particles.
\end{abstract}

\section{Giriş (Introduction)}

Bor karbür $\left(B_{4} C\right)$, kovalent bağlı $B_{11} C$ ikosahedral ve genellikle $C-B-C$ üç atomlu lineer zinciri içeren (C-C-C veya $\mathrm{C}-\mathrm{B}-\mathrm{B}$ zincirlerini de içerebilir) rombohedral yapıya sahip, ileri teknoloji bir seramik malzemedir [1]. Sahip olduğu özel kristal yapı ve güçlü kovalent bağları sayesinde, yüksek sertlik, yüksek ergime noktası, yüksek elastisite modülü, kimyasal korozyona karşı yüksek dayanım, üstün termoelastik ve termoelektrik özellikler ve düşük yoğunluk gibi önemli özelliklere sahiptir [1,2]. 
Bor karbür, giyilebilir zırhlarda ve zırhlı araçlarda zırh malzemesi olarak; ısıya dirençli kaplamalarda, sermetlerde katkı maddesi olarak ve taşlama, parlatma gibi yüzey işlemlerinde aşındırıcı olarak kullanılmaktadır [3-5]. Ayrıca bor karbür yüksek ısı üretim kapasitesine sahip olmasından dolayı roketlerde katı yakıt malzemesi olarak da kullanılmaktadır [1,3-7]. Bu üstün özelliklerinden dolayı stratejik alanlarda tercih edilen bir malzemedir. Bu nedenle bor karbür tozlarını kompakt hale getirmek için düşük tane boyutlu olması mekanik özellikleri açısından fayda sağlamaktadır. Ayrıca sentezleme sonrası kırma ve öğütme gibi işlemlerin azalması, ticari üretimde ekonomiklik açısından çok önemlidir [8].

Mikron altı ve nano boyutlarda bor karbür tozlarının sentezlenmesi için elemental sentez [2,9,10], kimyasal buhar biriktirme (CVD) [2,9], magnezotermik indirgeme ve karbotermik indirgeme (CTR) [11,12] gibi farklı yöntemler kullanılmıştır. Ancak bunlardan elemental sentez yöntemi, element halindeki borun fiyatları ve yüksek reaksiyon süreleri ve sıcaklıkları $\left(1800-2200^{\circ} \mathrm{C}\right)$ nedeniyle ticari değildir ve çok stratejik ürünler için özel olarak ve az miktarlarda üretimi yapılmaktadır [10]. Kimyasal buhar biriktirme (CVD) yöntemi ise, kullanılan gazlı bileşiklerin ve reaksiyon için gerekli ekipmanın yüksek maliyetinden dolayı ticari üretime uygun değildir [2]. Magnezotermik indirgeme, sentez sırasında gerekli enerjinin büyük kısmını magnezyumdan sağlar ancak sonrasından yapıdan magnezyumlu bileşiği uzaklaştırmak için sıcak asitlerle yıkama işlemi gerektirir ve bir miktar safsızlık yapıda hep bulunmaktadır $[9,11,13-15]$.

Karbotermik indirgeme (CTR) yöntemi maliyet açısından ve karmaşık olmayan ekipman kullanımı nedeniyle ticari olarak en çok tercih edilen yöntemdir $[16,17]$. CTR yönteminde başlangıç malzemesinin esnekliği ve düşük sıcaklıklarda sentezlenmeye imkan tanıması, mikroyapıyı kontrol edebilme gibi avantajlar bulunmaktadır $[8,18,19]$. B $\mathrm{C}$ tozu ticari olarak yüksek sıcaklıkta (genellikle $1750^{\circ} \mathrm{C}$ 'nin üzerinde) bor oksit $\left(\mathrm{B}_{2} \mathrm{O}_{3}\right)$ ve karbon tozunun karbotermik indirgenmesi ile sentezlenir [20]. Endotermik bir reaksiyon olduğu için bor oksit $\left(\mathrm{B}_{2} \mathrm{O}_{3}\right)$ ve karbonun reaksiyona girmesi uzun zaman ve yüksek enerji gerektirir. Bor karbürün başlangıç malzemelerini karıştırmak için mekanik yöntemler kullanılarak yüksek sıcaklıklarda elde edilen bor karbürü daha düşük sıcaklıklarda elde etmek mümkündür.

Mekanik aktivasyon ile bilyeli öğütücülerde yüksek hızlarda karıştırılan bor oksit ve karbon kaynaklarının tane boyutunun düşmesi ve homojen bir şekilde karışmasının reaksiyon sıcaklıklarını düşürüceği düşünülmektedir [21]. Bu çalışmanın amacı, mekanik olarak aktive edilen başlangıç hammaddesi tozların nispeten düşük sıcaklıklarda reaksiyonu ile bor karbür tozların eldesi ve kullanılan farklı karbon kaynaklarının faz oluşumu ve son ürün mikroyapısı üzerindeki etkisinin incelenmesidir.

\section{Malzemeler ve yöntemler (Materials and methods)}

$\mathrm{Bu}$ çalışmada, $\mathrm{B}_{2} \mathrm{O}_{3}$ (Eti Maden, \%98 saflık, $250 \mu \mathrm{m}$ ortalama partikül boyutu) bor kaynağı olarak ve grafit (Merck, <50 $\mu \mathrm{m}$ partikül boyutu) ve aktif karbon (Merck, <30 $\mu \mathrm{m}$ partikül boyutu) iki farklı karbon kaynağı olarak kullanılmıştır. Karbon kaynaklarının XRF sonuçları Çizelge 1'de verilmiştir. Çizelge 1'den görüldüğü üzere, aktif karbonun içerdiği empürite miktarının fazla olduğu; grafitin ise yüksek saflıkta olduğu gözlemlenmiştir. Farklı saflık derecesine sahip karbon kaynaklarının kullanımının nedeni, son ürün özellikleri ve reaksiyon verimi üzerinde karbon kaynağının etkisinin incelenmesidir.

Karbon kaynaklarına ve başlangıç tozlarına ait SEM görüntüleri ve XRD paternleri Şekil 1'de sunulmuştur. Şekil 1(a) ve (b) birbiriyle karşılaştırıldığında, morfoloji farklılığı belirgindir: Grafit küresel ve eş eksenli aglomere tozlardan oluşurken, aktif karbon iğnemsi ve keskin uçlara sahip kırılgan yapılardan oluşmaktadır. Şekil 1(c) ve (d)'de sunulan grafit ve aktif karbon tozlarına ait XRD paternlerindeki tüm pikler $C$ fazına aittir. Şekil 1(c) ve (d) birbiriyle karşılaştırıldığında, grafitin kristalin yapıda olduğu; aktif karbonun ise amorf yapıda olduğu ve $C$ fazına ait bazı kristalin pikleri içerdiği gözlemlenmektedir.

Toz karışımları eşitlik (1)'de verilen reaksiyona göre stokiyometrik ve $\% 25$ stokiyometri fazlası $\mathrm{B}_{2} \mathrm{O}_{3}$ içeren oranlarda hazırlanmıştır.

$$
2 \mathrm{~B}_{2} \mathrm{O}_{3(\mathrm{k})}+7 \mathrm{C}_{(\mathrm{k})} \rightarrow \mathrm{B}_{4} \mathrm{C}_{(\mathrm{k})}+6 \mathrm{CO}_{(\mathrm{g})}
$$

Hazırlanan toz karışımlarına (6 g), Retsch öğütücü kullanılarak 350 devir/dk hız ve 3 sa süre ile mekanik aktivasyon işlemi uygulanmıştır. Deney sonuçlarına göre, grafit ve aktif karbon kaynaklarının farklı etkilerini gözlemlemek amacıyla, grafit kullanılan deneylerde öğütme hızı (600 devir/dk) ve aktif karbon kullanılan deneylerde ise öğütme süresi (6 sa) artırılmıştır. Öğütme deneylerinde agat öğütme kapları ve bilyeler kullanılmıştır ve bilye/toz oranı 4/1 olarak sabit tutulmuştur. Tüm toz hazırlama işlemleri (vakum ve Ar ile temizlenen) MBraun kapalı ortam kutusunda gerçekleştirilmiştir. Şekil 1(e) ve (f)'de grafit- $\mathrm{B}_{2} \mathrm{O}_{3}$ (3 sa öğütme) ve (f) aktif karbon- $\mathrm{B}_{2} \mathrm{O}_{3}$ (350 devir/dk) toz karışımlarına ait XRD paternleri sunulmuştur. XRD paternlerinde sadece $\mathrm{B}_{2} \mathrm{O}_{3}$ (ICCD No: 00-006-0297) ve C (ICDD No: 00026-1079) fazlarına rastlanması, öğütme sonrasında

Çizelge 1. Aktif karbon ve grafit kimyasal analiz sonuçları (Chemical analyses of active carbon and graphite).

\begin{tabular}{llllllllll}
\hline (\% ağ.) & C & Ca & Si & Al & Na & Fe & S & Mg & P \\
\hline Aktif C & 92,80 & 1,66 & 1,49 & 0,86 & 0,83 & 0,71 & 0,63 & 0,60 & 0,14 \\
Grafit & 99,80 & 0,04 & 0,03 & - & - & 0,02 & 0,03 & - & 0,06 \\
\hline
\end{tabular}


başlangıç tozları arasında herhangi bir reaksiyonun gerçekleşmediğini göstermektedir. Şekil 1(e)'de verilen XRD paternindeki Rietveld analizine göre, grafit kullanıldığı durumda öğütme hızındaki artış, C fazının kristalit boyutunda düşüşe neden olmaktadır. Aynı koşullarda aktif karbon- $\mathrm{B}_{2} \mathrm{O}_{3}$ toz karışımı öğütüldüğünde ise (Şekil 1(f), $\mathrm{C}$ fazı neredeyse tamamen amorflaşarak XRD paterninde oldukça düşük şiddetli pikleri gözlemlenebilmektedir. Şekil 1(f)'de verilen XRD paternindeki Rietveld analizine göre, aktif karbon kullanıldığı durumda, öğütme süresindeki artış $\mathrm{B}_{2} \mathrm{O}_{3}$ fazının kristalit boyutunda düşüşe yol açmaktadır.
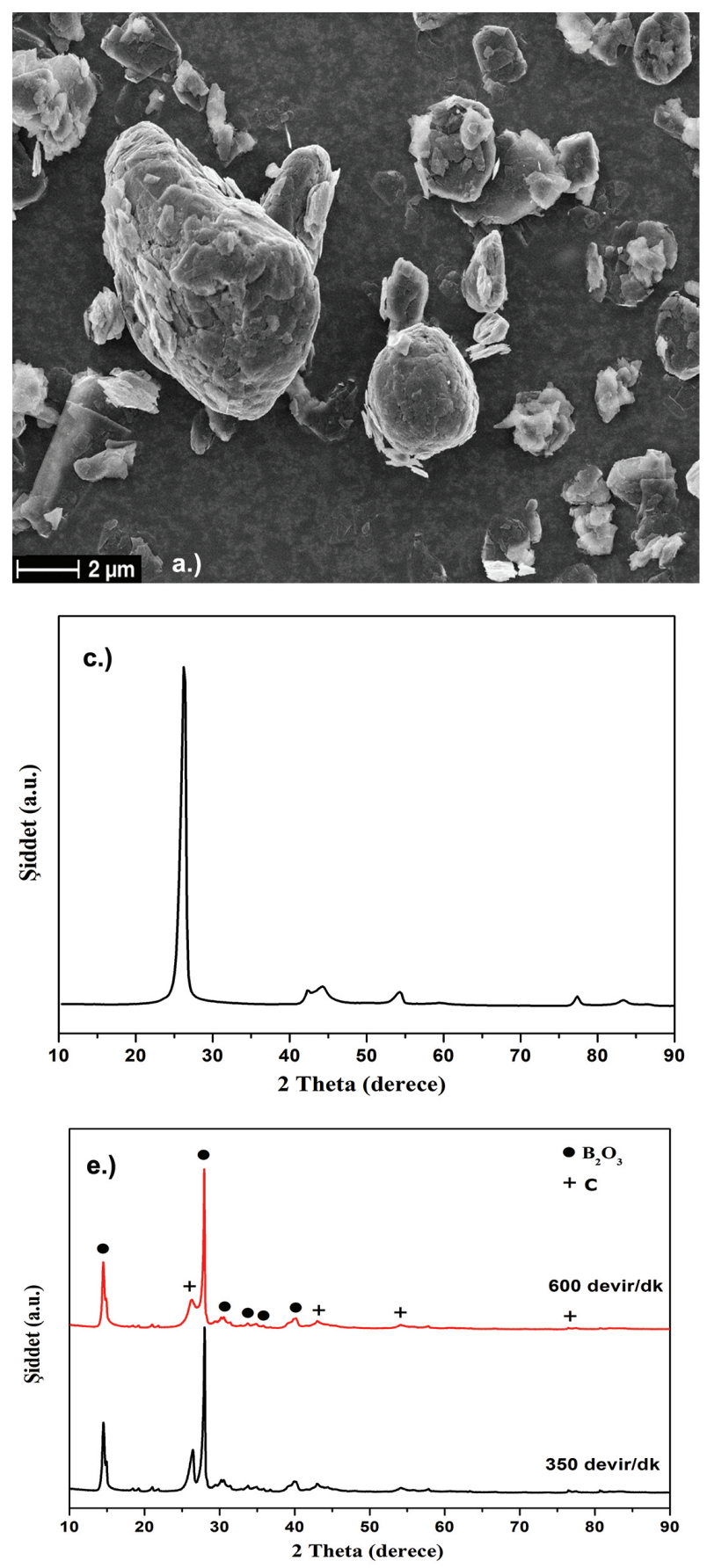

Stokiyometrik ve stokiyometri fazlası $\mathrm{B}_{2} \mathrm{O}_{3}$ içeren miktarlarda hazırlanan ve mekanik aktivasyon uygulanan toz karışımları, hidrolik preste sıkıştırılarak peletler haline getirilmiş ve Argon altında çalışan tüp fırına alumina kayıkçıklar içinde yerleştirilmiştir. Kullanılan tüp fırın Protherm marka $1450^{\circ} \mathrm{C}$ maksimum sıcaklıkta çalışabilen yatay tüp fırındır. Yapılan deneysel çalışmaların tümü, Argon atmosferinde $8^{\circ} \mathrm{C} / \mathrm{dk}$ hızla $1450^{\circ} C^{\prime}$ ye çıkarak ve burada 6 saat bekleyip fırında yavaş soğuma döngüsü ile tekrarlanmıştır. Fırın ısıtılmaya başlanmadan önce tüp içindeki havanın boşaltılması için $5 \mathrm{dk}$ boyunca vakum altında tutulmuştur.
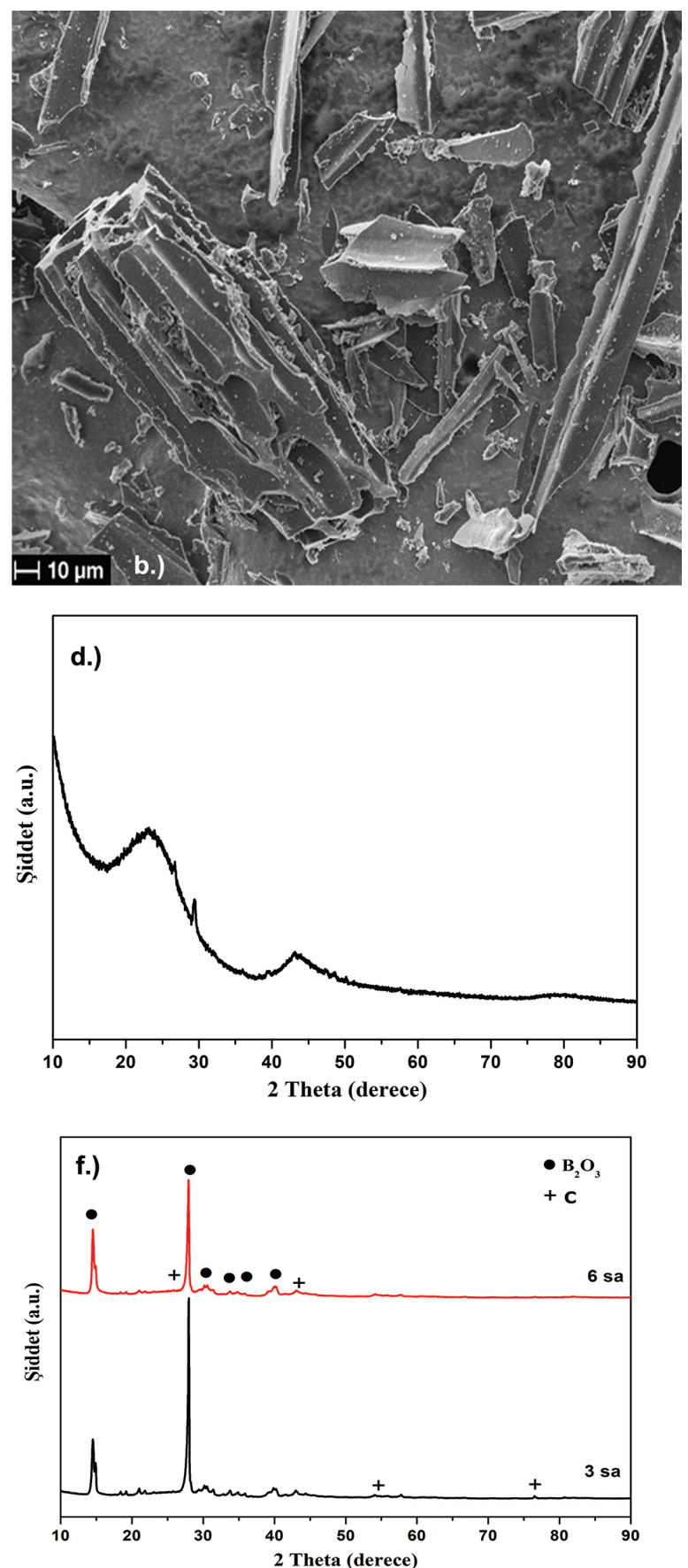

Şekil 1. Karbon kaynaklarına ve başlangıç tozlarına ait SEM görüntüleri ve XRD paternleri: (a) Grafit, (b) aktif karbon tozlarına ait SEM görüntüleri ve (c) grafit, (d) aktif karbon tozlarına ait XRD paternleri ve (e) grafit- $\mathrm{B}_{2} \mathrm{O}_{3}$ (3 sa öğütme) ve (f) aktif karbon- $\mathrm{B}_{2} \mathrm{O}_{3}$ (350 devir/dk) toz karışımlarına ait XRD paternleri (SEM images and XRD patterns of the carbon sources and starting materials: SEM images of (a) graphite, (b) active carbon, and XRD patterns of (c) graphite, (d) active carbon and XRD patterns of (e) graphite- $\mathrm{B}_{2} \mathrm{O}_{3}$ powder blends ( $3 \mathrm{~h}$ milling), (f) active carbon- $\mathrm{B}_{2} \mathrm{O}_{3}$ powder blends $(350 \mathrm{rpm})$ ). 
Reaksiyon sonucu oluşan CO gazı, akış halindeki Argon gazı sayesinde gaz yıkama şişesi yardımıyla çeker ocakların içinden süpürülmüştür.

Üretilen tozların faz analizleri ve mikroyapısal karakterizasyonu, X-ışınları difraktometresi (XRD, Bruker D8, CuKa) ve yüksek çözünürlüklü taramaIı elektron mikroskobu/enerji dağılım spektrometresi (SEM/EDS, Zeiss Ultra Plus) kullanılarak gerçekleştirilmiştir. Son üründeki toplam karbon analizi, Thermo Scientific Flash 2000 organik element cihazında yapılmış ve teorik reaksiyonlardan yapılan hesaplamalara göre kalıntı karbon miktarı kantitatif olarak belirlenmiştir. Eşitlik (1)'de verilen reaksiyonun termal davranışı Netzsch STA449-F3 cihazı kullanılarak alumina pota içinde $1500^{\circ} \mathrm{C}$ 'ye kadar ısıtma (Ar altında) ile gözlemlenmiştir.

\section{Sonuçlar ve tartışma (Results and discussion)}

Şekil 2'de 3 sa mekanik olarak aktive edilen (350 devir/dk) ve $1450^{\circ} \mathrm{C}$ 'de tüp fırında reaksiyona giren stokiyometrik $\mathrm{B}_{2} \mathrm{O}_{3}$-grafit toz karışımlarına ait XRD paterni sunulmuştur. XRD paterninden görüldüğü üzere, $\mathrm{B}_{4} \mathrm{C}$ fazı (ICDD No: 00-035-0798) oluşumu gerçekleşmiştir ancak yapıda yüksek oranda reaksiyona girmeden kalan C fazı (ICDD No: 01-071-3649) bulunmaktadır. Bu durum reaksiyonun tamamlanmadığını ve bor oksitin tükenerek fazla karbonun yapıda kaldığını göstermektedir. Aynı numuneye ait SEM görüntüleri Şekil 3'te sunulmuştur. Elde edilen ürünün yaklaşık partikül boyutu $10-80 \mu \mathrm{m}$ civarındadır.

Şekil 4'de 3 sa mekanik olarak aktive edilen (600 devir/dk) ve $1450^{\circ} \mathrm{C}$ 'de tüp fırında reaksiyona giren stokiyometrik $\mathrm{B}_{2} \mathrm{O}_{3}$-grafit toz karışımlarına ait XRD paterni sunulmuştur. Şekil 2 ve 4 karşılaştırıldığında, öğütme işleminin hızının 350'den 600 devir/dk'ya çıkarılması ile birlikte, $\mathrm{B}_{4} \mathrm{C}$ pik şiddetlerinde artış gözlemlenmiştir. Ancak yapıda kalan fazla miktardaki karbon giderilememiştir. Bu numuneye ait SEM görüntüleri Şekil 5'de sunulmuştur ve son ürünün 5-50 $\mu \mathrm{m}$ ortalama partikül boyutlarına sahip olduğu görülmüştür. Bu

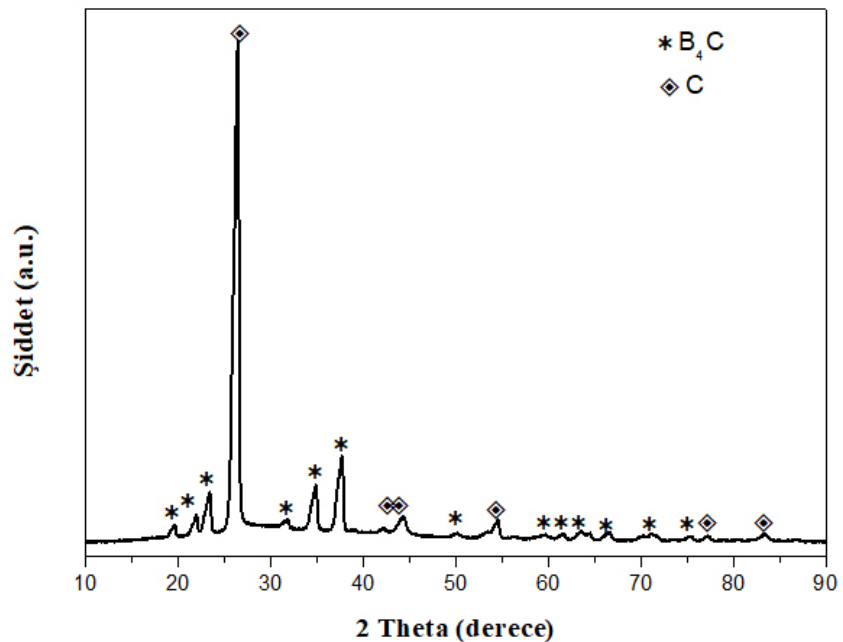

Şekil 2. 3 sa mekanik olarak aktive edilen (350 devir/dk) ve $1450^{\circ} \mathrm{C}$ 'de tüp fırında reaksiyona giren stokiyometrik $\mathrm{B}_{2} \mathrm{O}_{3}$ grafit toz karışımlarına ait XRD paterni (XRD pattern of stoichiometric $\mathrm{B}_{2} \mathrm{O}_{3}$-graphite powder blends mechanically activated for $3 \mathrm{~h}$ (350 rpm) and reacted at $1450^{\circ} \mathrm{C}$ in tube furnace).

durum mekanik aktivasyon hızının artması ile birlikte sentez sonrası son partikül boyutunun küçüldüğünü göstermektedir. SEM görüntüleri, farklı öğütme hızları ile hazırlanan ve $1450^{\circ} \mathrm{C}$ 'de tüp fırında reaksiyon sonucu elde edilen $\mathrm{B}_{4} \mathrm{C}-\mathrm{C}$ faz karışımına sahip ürünün serbest toz halinde elde edildiğini ve yapıda herhangi bir sinterleşmenin olmadığını kanıtlamaktadır. Organik element analizi sonuçlardan yapılan hesaplamalara göre, Şekil 2 ve 4'de XRD paternleri sunulan bu tozların yapısında en az \% 13-15 arasında serbest karbon bulunduğu saptanmıştır.

Şekil 6 ve 7'de 3 sa mekanik olarak aktive edilen (350 devir/dk) ve $1450^{\circ} \mathrm{C}$ 'de tüp fırında reaksiyona giren stokiyometrik $\mathrm{B}_{2} \mathrm{O}_{3}$-aktif $\mathrm{C}$ toz karışımlarına ait XRD paterni ve SEM görüntüleri sunulmuştur. Aynı koşullardaki mekanik aktivasyon ve aynı sıcaklık/süredeki reaksiyon sonrasında, karbon kaynağı olarak aktif karbon kullanımının (Şekil 6) grafit kullanımı (Şekil 2) ile karşılaştırıldığında, son üründeki kalıntı karbon miktarını
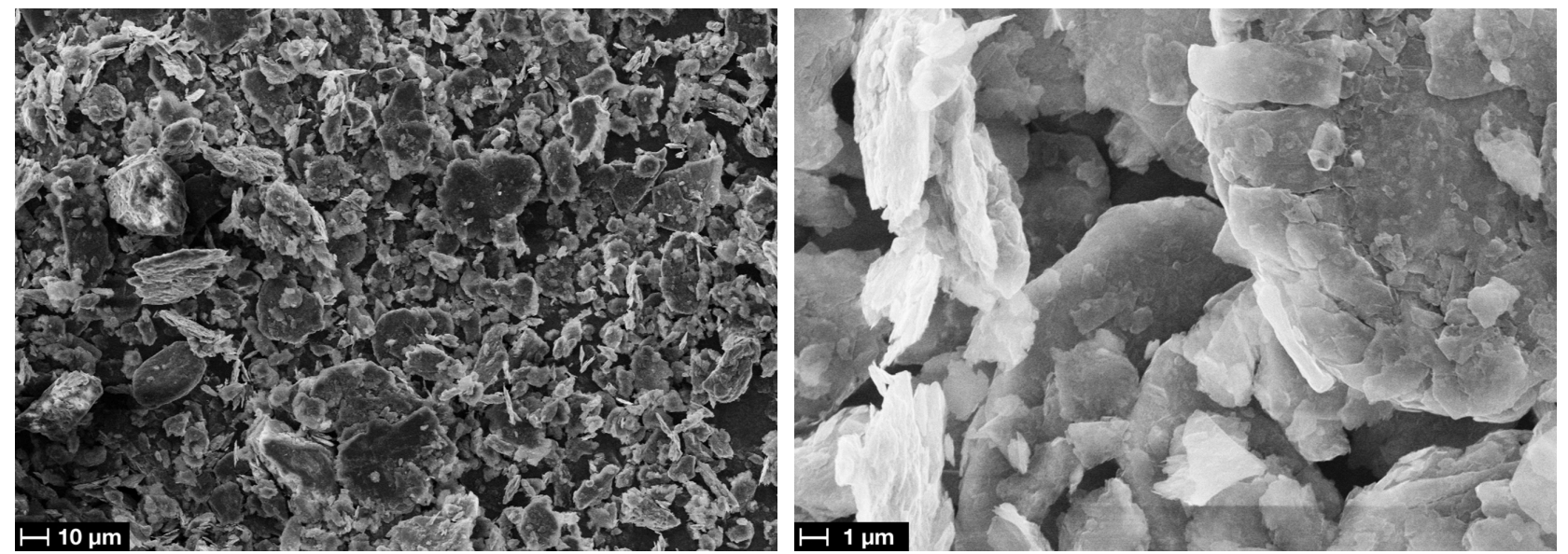

Şekil 3. 3 sa mekanik olarak aktive edilen ( $350 \mathrm{devir} / \mathrm{dk}$ ) ve $1450^{\circ} \mathrm{C}$ 'de tüp fırında reaksiyona giren stokiyometrik $\mathrm{B}_{2} \mathrm{O}_{3}$-grafit toz karışımlarına ait SEM görüntüleri (SEM images of stoichiometric $\mathrm{B}_{2} \mathrm{O}_{3}$-graphite powder blends mechanically activated for $3 \mathrm{~h}$ (350 $\mathrm{rpm}$ ) and reacted at $1450^{\circ} \mathrm{C}$ in tube furnace). 


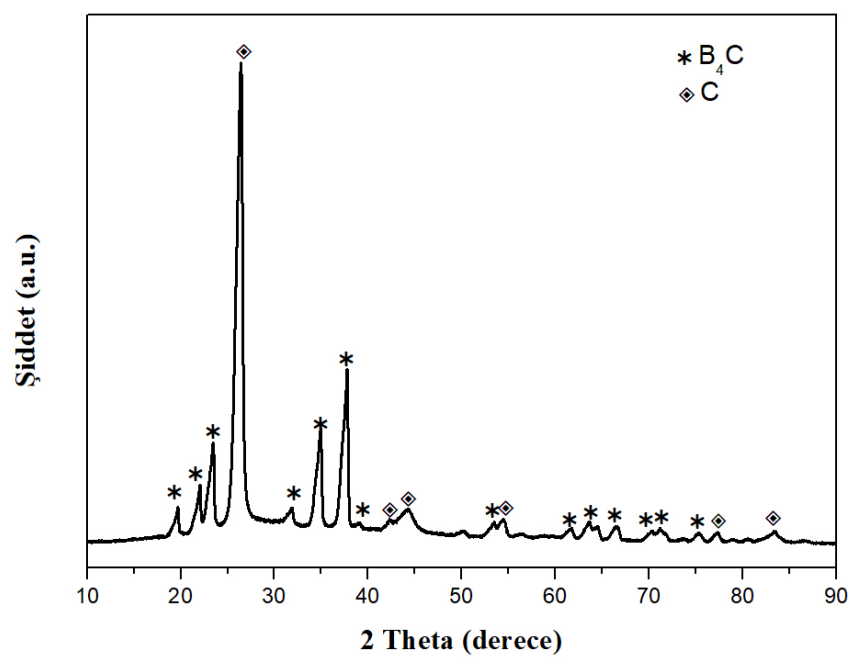

Şekil 4. 3 sa mekanik olarak aktive edilen (600 devir/dk) ve $1450^{\circ} \mathrm{C}$ 'de tüp fırında reaksiyona giren stokiyometrik $\mathrm{B}_{2} \mathrm{O}_{3}-$ grafit toz karışımlarına ait XRD paterni (XRD pattern of stoichiometric $\mathrm{B}_{2} \mathrm{O}_{3}$-graphite powder blends mechanically activated for $3 \mathrm{~h}$ $(600 \mathrm{rpm})$ and reacted at $1450^{\circ} \mathrm{C}$ in tube furnace).

önemli ölçüde azalttığı gözlemlenmiştir. Şekil 6'da görüldüğü üzere, yapıdaki kalıntı karbon miktarı oldukça azdır. Organik element analizi sonuçlardan yapılan hesaplamalara göre, son ürün yapısında ağırlıkça \% 4 oranında serbest karbon içermektedir. Bunun yanında, yapıda borca zengin bor karbür fazlarına ait şiddeti düşük pikler bulunmaktadır.

Şekil 7'deki SEM görüntüsünde ortalama partikül boyutunun yaklaşık 5-30 $\mu \mathrm{m}$ aralığında olduğu saptanmıştır. SEM görüntüsü üzerinde yapılan hesaplamalara göre, tozların ortalama partikül boyutu 10 $\mu$ m'dir. Bu durum aktif karbon kullanımının grafit kullanımına oranla son ürün partikül boyutunu düşürdüğünü göstermektedir. Her iki karbon kaynağıyla sentezlenen toz ürünlerin genel görünümü topaklanmış şekildedir. Şekil 7'de sunulan EDS analizine göre, elde edilen tozun yapısında ağırlıkça \% 73,1, 25,7 ve 1,27 oranlarında $\mathrm{B}, \mathrm{C}$ ve $\mathrm{O}$ elementleri saptanmıştır. EDS analizinde saptanan az miktardaki $\mathrm{O}$ elementinin, atmosferik koşullar nedeniyle oluşan yüzey oksitlenmesinden kaynaklandığı düşünülmektedir.

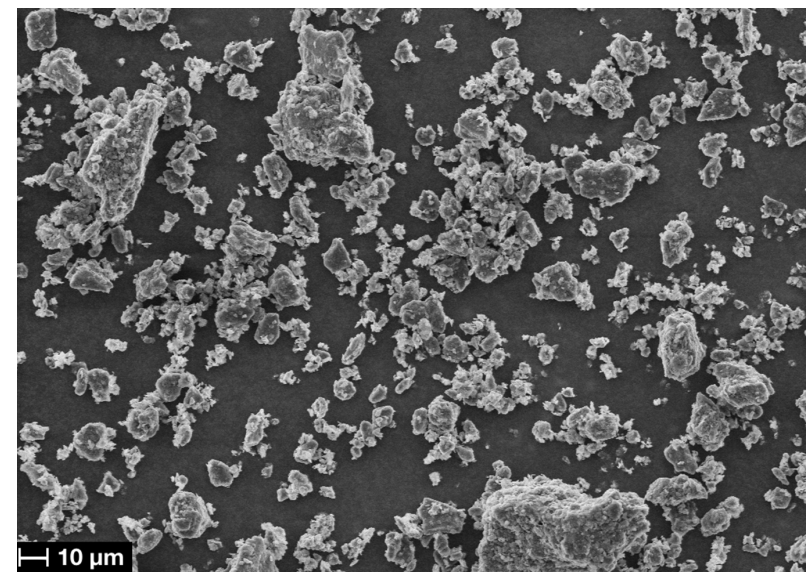

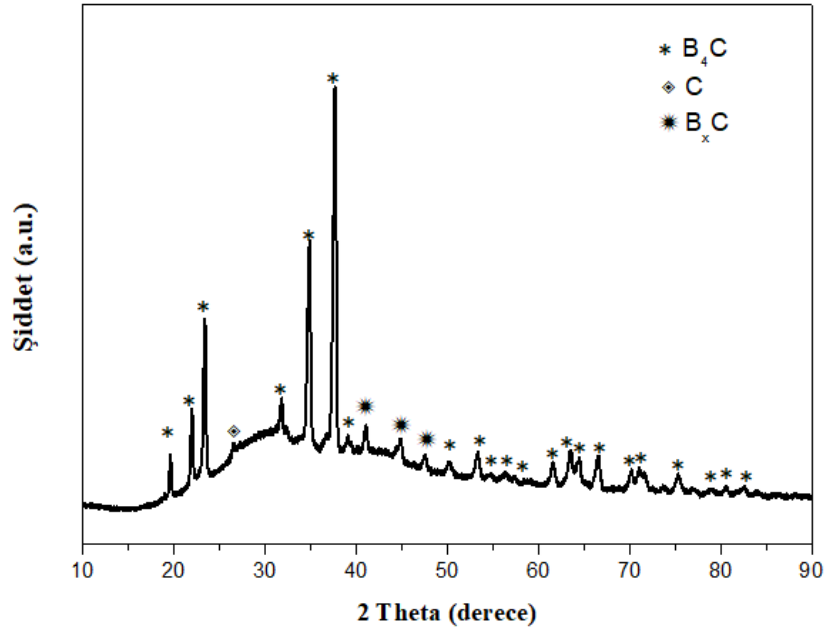

Sekil 6. 3 sa mekanik olarak aktive edilen (350 devir/dk) ve $1450^{\circ} \mathrm{C}$ 'de tüp fırında reaksiyona giren stokiyometrik $\mathrm{B}_{2} \mathrm{O}_{3}-$ aktif $\mathrm{C}$ toz karışımlarına ait XRD paterni (XRD pattern of stoichiometric $\mathrm{B}_{2} \mathrm{O}_{3}$-active carbon powder blends mechanically activated for $3 \mathrm{~h}(350 \mathrm{rpm})$ and reacted at $1450^{\circ} \mathrm{C}$ in tube furnace $)$.

Mekanik aktivasyon süresinin son ürün üzerindeki etkisini gözlemlemek amacıyla, 6 sa mekanik olarak aktive edilen tozlar aynı koşullarda reaksiyona sokulmuştur. Şekil 8'de 3 ve 6 sa mekanik olarak aktive edilen (350 devir/dk) ve $1450^{\circ} \mathrm{C}$ 'de tüp fırında reaksiyona giren stokiyometrik $\mathrm{B}_{2} \mathrm{O}_{3}$-aktif $\mathrm{C}$ toz karışımlarına ait XRD paternleri karşılaştırma amacıyla birlikte sunulmuştur. Mekanik aktivasyon süresinin uzatılması birlikte kararsız $B_{x} C$ pik şiddetlerinde azalma görülmüştür. Öte yandan, az miktarda SiC oluşumu gerçekleşmiş olup, bu durum uzun süren öğütme işlemi sonucu (6 sa), aktif karbon yapısında bulunan Si empüritesinin (Çizelge 1) C ile reaksiyona girmesiyle bağlantılandırılabilir. Bunun yanında, 6 sa öğütme sonucunda öğütme bilyelerinde ağırıı kaybı olmayıp, öğütme kabında az miktarda aşınma gözlemlenmiştir. Bu durum da, öğütme sırasında toz içerisine az miktarda Si empüritesinin geçmesine neden olmuştur.

Şekil 9'da aynı numunelere ait SEM görüntüleri 1000X büyütmede karşılaştırmalı olarak sunulmuştur.

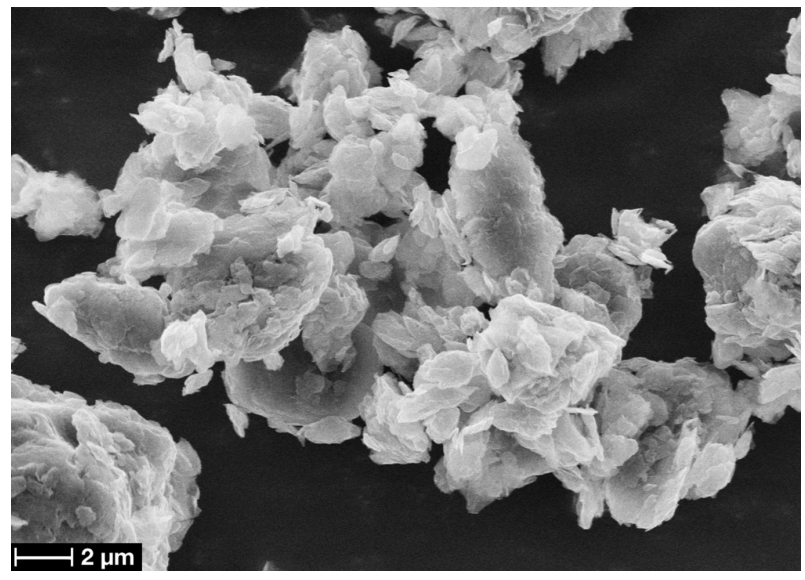

Şekil 5. 3 sa mekanik olarak aktive edilen $\left(600\right.$ devir/dk) ve $1450^{\circ} \mathrm{C}$ 'de tüp fırında reaksiyona giren stokiyometrik $\mathrm{B}_{2} \mathrm{O}_{3}$-grafit toz karışımlarına ait SEM görüntüleri (SEM images of stoichiometric $\mathrm{B}_{2} \mathrm{O}_{3}$-graphite powder blends mechanically activated for $3 \mathrm{~h}(600$ $\mathrm{rpm}$ ) and reacted at $1450^{\circ} \mathrm{C}$ in tube furnace). 

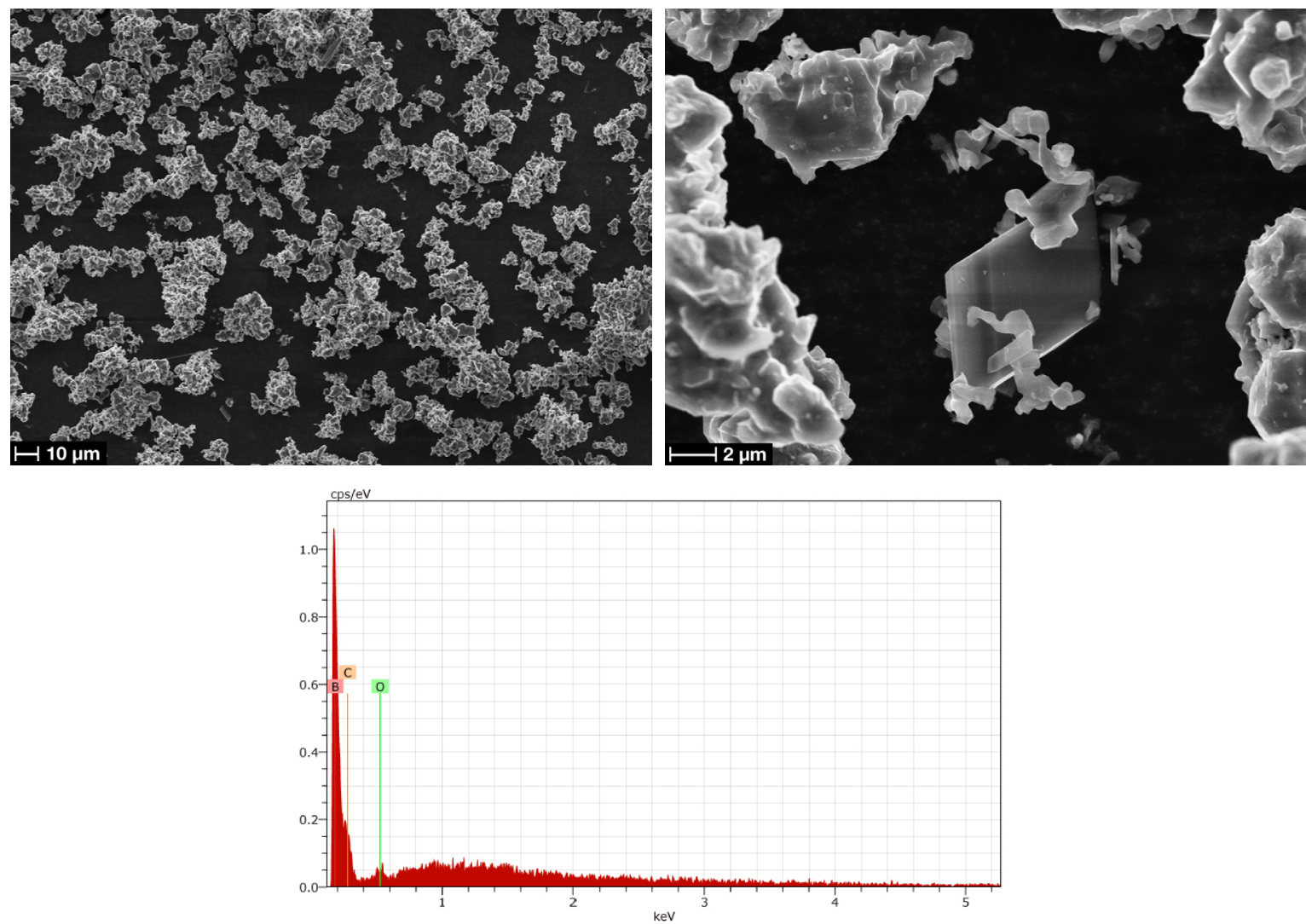

Şekil 7. 3 sa mekanik olarak aktive edilen (350 devir/dk) ve $1450^{\circ} \mathrm{C}$ 'de tüp fırında reaksiyona giren stokiyometrik $\mathrm{B}_{2} \mathrm{O}_{3}$-aktif $\mathrm{C}$ toz karışımlarına ait SEM görüntüleri ve EDS analizi (SEM images and EDS analysis of stoichiometric $\mathrm{B}_{2} \mathrm{O}_{3}$-active carbon powder blends mechanically activated for $3 \mathrm{~h}(350 \mathrm{rpm})$ and reacted at $1450^{\circ} \mathrm{C}$ in tube furnace).

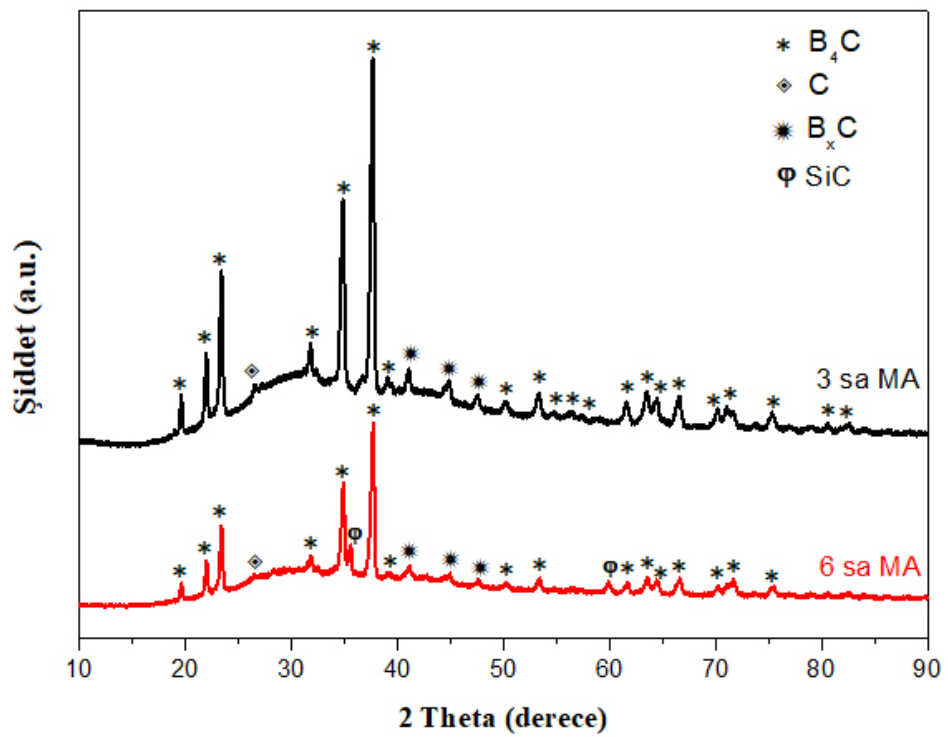

Şekil 8. 3 ve 6 sa mekanik olarak aktive edilen (350 devir/dk) ve $1450^{\circ} C^{\prime}$ de tüp fırında reaksiyona giren stokiyometrik $B_{2} \mathrm{O}_{3}$ aktif $\mathrm{C}$ toz karışımlarına ait XRD paternleri (XRD patterns of stoichiometric $\mathrm{B}_{2} \mathrm{O}_{3}$-active carbon powder blends mechanically activated for 3 and $6 \mathrm{~h}(350 \mathrm{rpm})$ and reacted at $1450^{\circ} \mathrm{C}$ in tube furnace)

Öğütme süresindeki artışın son ürün ortalama partikül boyutu üzerinde kayda değer bir değişim sağlamadığı gözlemlenmiştir.

Yapıda az miktarda kalan kalıntı karbonun azaltılması amacıyla, başlangıçta stokiyometrik olan $\mathrm{B}_{2} \mathrm{O}_{3}$ miktarı, $\% 25$ stokiyometri fazlası olacak şekilde artırımış ve aynı koşullarda reaksiyon tekrarlanmıştır. Şekil 10'da
3 sa mekanik olarak aktive edilen (350 devir/dk) ve $1450^{\circ} \mathrm{C}$ 'de tüp fırında reaksiyona giren stokiyometrik ve $\% 25$ fazla $\mathrm{B}_{2} \mathrm{O}_{3}$ içeren $\mathrm{B}_{2} \mathrm{O}_{3}$-aktif $\mathrm{C}$ toz karışımlarına ait XRD paternleri karşılaştırma amacıyla birlikte sunulmuştur. Fazla $\mathrm{B}_{2} \mathrm{O}_{3}$ kullanımı, reaksiyon verimini artırmış ve kalıntı karbon ve kararsız $\mathrm{B}_{\mathrm{x}} \mathrm{C}$ pikleri azalmıştır. Ancak yapıda düşük şiddetli tanımlanamayan pikler oluşmuştur. 

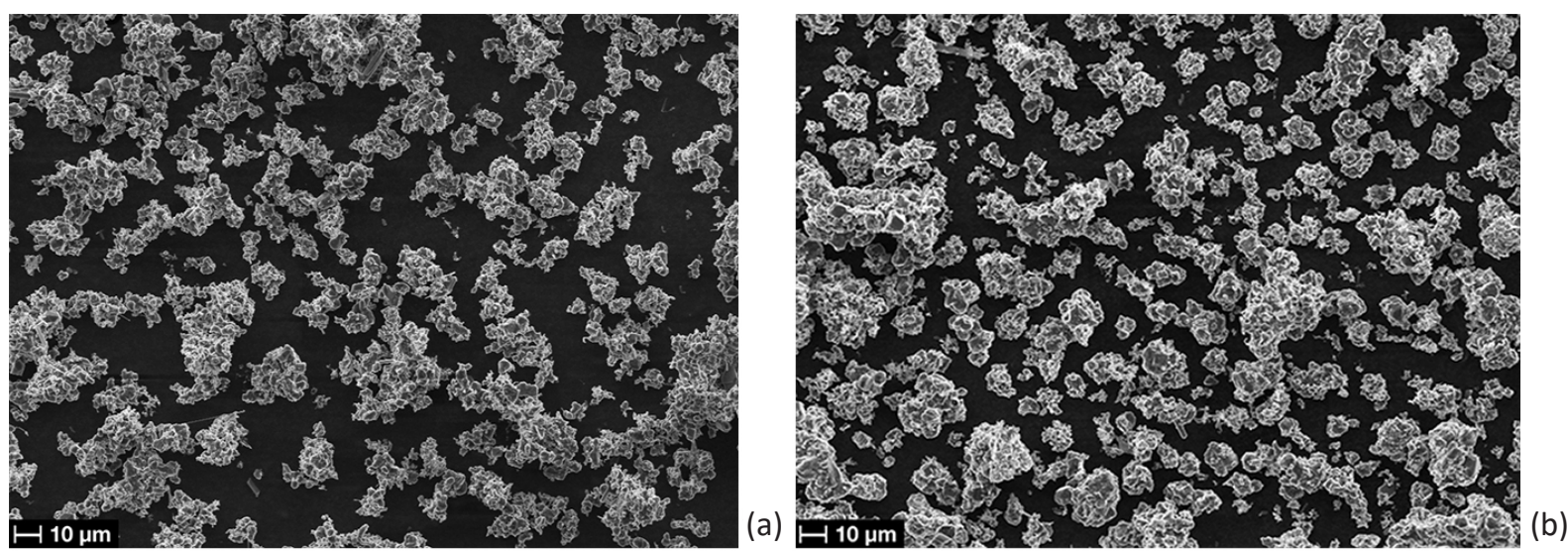

Şekil 9. (a) 3 sa ve (b) 6 sa mekanik olarak aktive edilen ( 350 devir/dk) ve $1450^{\circ} \mathrm{C}$ 'de tüp fırında reaksiyona giren stokiyometrik $\mathrm{B}_{2} \mathrm{O}_{3}$-aktif $\mathrm{C}$ toz karışımlarına ait SEM görüntüleri (SEM images of stoichiometric $\mathrm{B}_{2} \mathrm{O}_{3}$-active carbon powder blends mechanically activated for(a) 3 and (b) $6 \mathrm{~h}$ (350 rpm) and reacted at $1450^{\circ} \mathrm{C}$ in tube furnace).

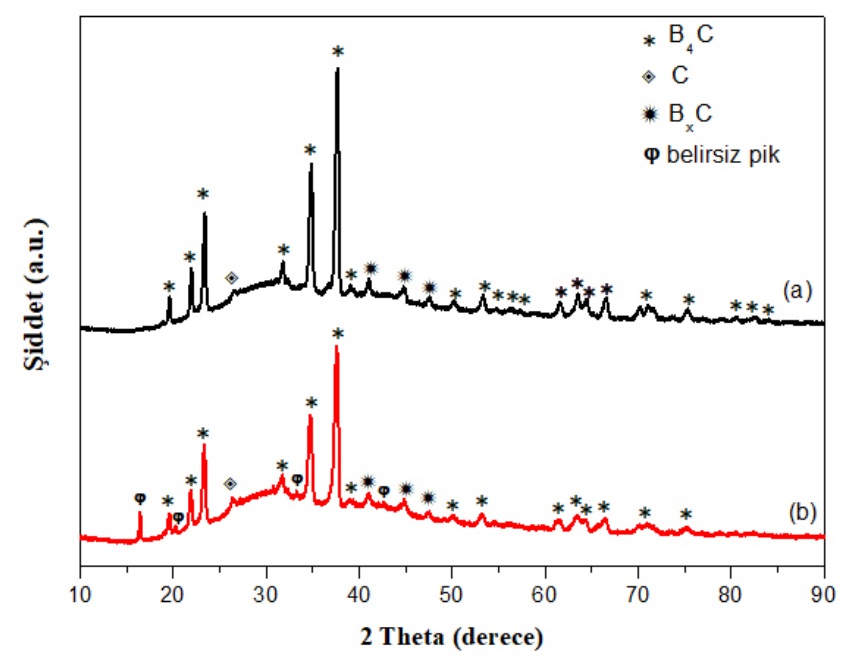

Şekil 10. 3 sa mekanik olarak aktive edilen (350 devir/dk) ve $1450^{\circ} \mathrm{C}$ 'de tüp fırında reaksiyona giren (a) stokiyometrik ve (b) \%25 fazla $\mathrm{B}_{2} \mathrm{O}_{3}$ içeren $\mathrm{B}_{2} \mathrm{O}_{3}$-aktif $\mathrm{C}$ toz karışımlarına ait XRD paternleri (XRD patterns of $\mathrm{B}_{2} \mathrm{O}_{3}$-active carbon powder blends prepared by (a) stoichiometric and (b) $25 \%$ stoichiometric excess amount of $\mathrm{B}_{2} \mathrm{O}_{3}$, mechanically activated for $3 \mathrm{~h}(350 \mathrm{rpm})$ and reacted at $1450^{\circ} \mathrm{C}$ in tube furnace)

Başlangıç hammaddesi olarak kullanılan fazla $\mathrm{B}_{2} \mathrm{O}_{3}$ miktarının grafit kullanıldığı durumdaki etkisini gözlemlemek amacıyla, $\mathrm{B}_{2} \mathrm{O}_{3}$-grafit toz karışımları \%25 fazla $\mathrm{B}_{2} \mathrm{O}_{3}$ kullanılarak hazırlanmış ve aynı koşullarda reaksiyon tekrarlanmıştır. Şekil 11 'de 3 sa mekanik olarak aktive edilen (350 devir/dk) ve $1450^{\circ} \mathrm{C}^{\prime}$ de tüp firında reaksiyona giren stokiyometrik ve $\% 25$ fazla $\mathrm{B}_{2} \mathrm{O}_{3}$ içeren $\mathrm{B}_{2} \mathrm{O}_{3}$-grafit toz karışımlarına ait XRD paternleri karşılaştırma amacıyla birlikte sunulmuştur. $\mathrm{B}_{2} \mathrm{O}_{3}$-grafit toz karışımlarının fazla $\mathrm{B}_{2} \mathrm{O}_{3}$ kullanımı ile reaksiyonun da $\mathrm{B}_{2} \mathrm{O}_{3}$-aktif karbon toz karışımlarınınki ile benzer bir sonuç gözlemlenmiştir: Kalıntı karbon miktarı azalırken, yapıda istenmeyen ara faz oluşumu gerçekleşmiştir. Şekil 11'den görüldüğü üzere, yapıda az miktarda $\mathrm{Al}_{2} \mathrm{O}_{3}$ fazı bulunmaktadır. Fazla $\mathrm{B}_{2} \mathrm{O}_{3}$ kullanımı durumunda, alumina kayıkçık aşınmakta ve toz içerisine empürite olarak geçmektedir. Aynı numunelere ait SEM görüntüleri Şekil 12'de sunulmuştur. Şekil 12(b)'deki SEM görüntüsünden alınan EDS analizine

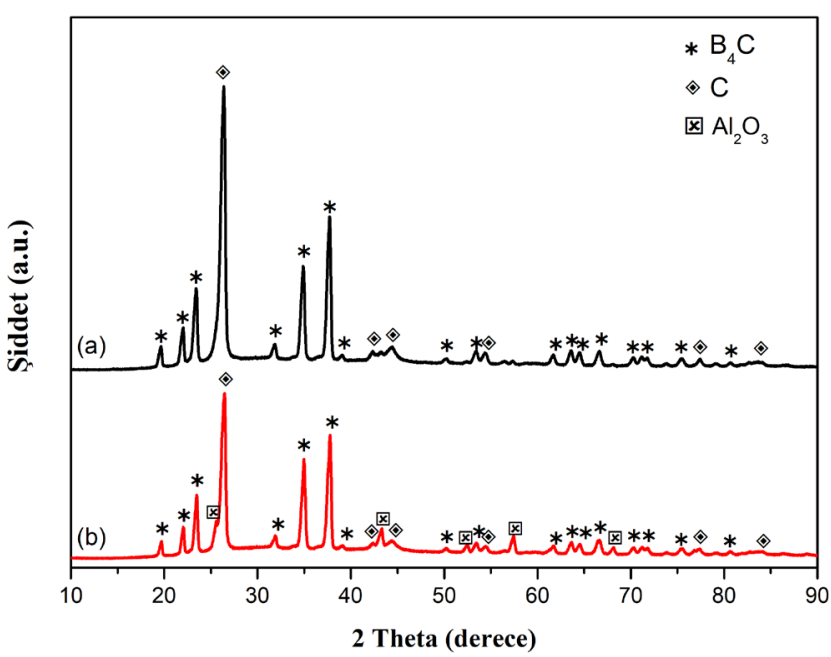

Şekil 11. 3 sa mekanik olarak aktive edilen (350 devir/dk) ve $1450^{\circ} \mathrm{C}$ 'de tüp fırında reaksiyona giren (a) stokiyometrik ve (b) \%25 fazla $\mathrm{B}_{2} \mathrm{O}_{3}$ içeren $\mathrm{B}_{2} \mathrm{O}_{3}$-grafit toz karışımlarına ait XRD paternleri (XRD patterns of $\mathrm{B}_{2} \mathrm{O}_{3}$-graphite powder blends prepared by (a) stoichiometric and (b) $25 \%$ stoichiometric excess amount of $\mathrm{B}_{2} \mathrm{O}_{3}$, mechanically activated for $3 \mathrm{~h}(350 \mathrm{rpm})$ and reacted at $1450^{\circ} \mathrm{C}$ in tube furnace).

göre (Şekil 12(c)), stokiyometri fazlası $\mathrm{B}_{2} \mathrm{O}_{3}$ içeren tozlardan elde edilen son tozlarda, sırasıyla ağırılıkça $\% 65,7,19,0,12,4$ ve 2,9 oranlarında $B, C$, O ve Al elementleri saptanmıştır. EDS analizi de tozların yapısında aluminyum oksit fazının bulunduğunu desteklemektedir. Özet olarak, \%25 fazla $\mathrm{B}_{2} \mathrm{O}_{3}$ içeren toz karışımlarında; aktif karbon kullanımında belirsiz piklerin (Şekil 10(b)), grafit kullanımında ise $\mathrm{Al}_{2} \mathrm{O}_{3}$ piklerinin (Şekil 11(b)) oluştuğu gözlemlenmiştir. Bu durum, stokiyometri fazlası reaktan kullanımının reaksiyon ortamı ile olan etkileşimi arttırdığını ve tesadüfi reaksiyon ürünlerinin oluşumuna yol açtığını göstermektedir. Grafit kullanıldığı durumda bu etkileşimin daha belirgin olmasının nedeni ise $\left(\mathrm{Al}_{2} \mathrm{O}_{3}\right.$ fazı oluşumu), stokiyometri fazlası $\mathrm{B}_{2} \mathrm{O}_{3}$-grafit arasında $\mathrm{B}_{2} \mathrm{O}_{3}$-aktif karbona göre nispeten daha az homojen bir karışımın oluşması, bunun neticesinde de sentez esnasında oluşan B-O arası fazların reaksiyon ortamı ile (alümina kayıkçık) daha kolay etkileşime girmesine yorumlanabilir. 

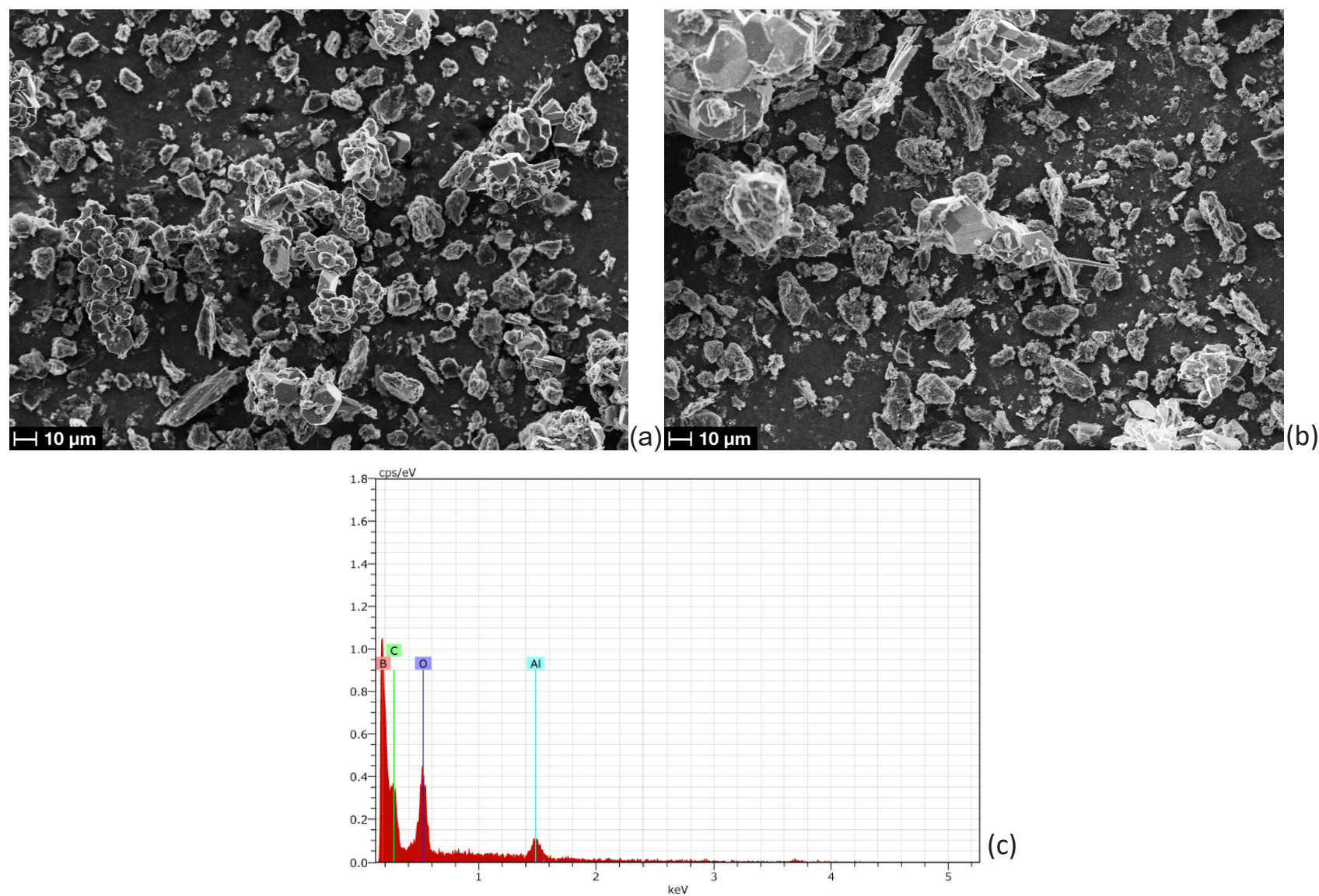

Şekil 12. 3 sa mekanik olarak aktive edilen (350 devir/dk) ve $1450^{\circ} \mathrm{C}$ 'de tüp fırında reaksiyona giren (a) stokiyometrik ve (b) $\% 25$ fazla $\mathrm{B}_{2} \mathrm{O}_{3}$ içeren $\mathrm{B}_{2} \mathrm{O}_{3}$-grafit toz karışımlarına ait SEM görüntüleri ve (c) \%25 fazla $\mathrm{B}_{2} \mathrm{O}_{3}$ içeren tozlara ait EDS analizi (SEM images and EDS analysis of $\mathrm{B}_{2} \mathrm{O}_{3}$-graphite powder blends prepared by (a) stoichiometric and (b) (c) $25 \%$ stoichiometric excess amount of $\mathrm{B}_{2} \mathrm{O}_{3}$, mechanically activated for $3 \mathrm{~h}(350 \mathrm{rpm})$ and reacted at $1450^{\circ} \mathrm{C}$ in tube furnace).

Çizelge 2 'de $1450^{\circ} \mathrm{C}^{\prime}$ de tüp fırında reaksiyona giren stokiyometrik toz karışımlarına ait deney koşulları ve sonuçları özetlenmiştir. Çizelge 2'den görüldüğü üzere, öğütme hızındaki artış faz yapısında değişime neden olmazken, partikül boyutunu düşürmektedir. Ögütme süresindeki artışın ise partikül boyutunda kayda değer bir değişim yaratmadığı için görülmüştür ve Çizelge'de sunulmamıştır. Öte yandan, aynı öğütme koşullarında aktif karbon kullanıldığında, grafite oranla son üründe serbest karbon önemli ölçüde azalmış ve ortalama partikül boyutu düşmüştür (Çizelge 2).

Karbon kaynağı olarak aktif karbon ile grafit kullanımı arasında reaksiyon kinetiği ve oluşum sıcaklığı üzerinde etkinin incelenmesi için aynı şartlar altında hazırlanmış iki başlangıç karışımı (stokiyometrik oran, 3 saat 350 devir/dk mekanik aktivasyon) DTA analizine tabi tutulmuştur.

Şekil 13'de aktif karbon ve grafit kullanımının reaksiyon sıcaklığı üzerindeki etkisi gösterilmiştir. Görüldüğü üzere, eksotermik karbotermik reaksiyon eşiği aktif karbon için $1360^{\circ} \mathrm{C}$ ile grafite göre $100^{\circ} \mathrm{C}$ daha düşük bir derecede gözlemlenmiştir. Farklı karbon kaynakları arasındaki partikül boyutu değişimi ve amorfluk/ kristalin yapıdaki farkılık, dolayısıyla reaktivite farkı nedeniyle reaksiyon ürünü oluşum sıcaklığında düşüş gözlemlenmektedir. Ayrıca 3 sa mekanik aktivasyonun da sıcaklık düşüşünde etkisi olmaktadır. Ancak her iki durumda da konvansiyonel reaksiyon sıcaklığı 1750$2000^{\circ} \mathrm{C}$ arasında olan $\mathrm{B}_{4} \mathrm{C}$ sentezinin daha düşük sıcaklıklara indirgenebileceği gösterilmiştir. Bu durum

Çizelge 2. $1450^{\circ} \mathrm{C}$ 'de tüp fırında reaksiyona giren stokiyometrik toz karışımlarına ait öğütme koşulları ve elde edilen faz ya$\mathrm{pısı/partikül} \mathrm{boyut} \mathrm{değerleri} \mathrm{(Milling} \mathrm{conditions,} \mathrm{resulting} \mathrm{phases} \mathrm{and} \mathrm{particle} \mathrm{sizes} \mathrm{of} \mathrm{powders} \mathrm{prepared} \mathrm{by} \mathrm{stoichiometric} \mathrm{powder} \mathrm{blends}$ after reaction at $1450^{\circ} \mathrm{C}$ in tube furnace).

\begin{tabular}{lllll}
\hline $\begin{array}{l}\text { Karbon } \\
\text { Kaynakları }\end{array}$ & Ögüütme Süresi & $\mathbf{3}$ sa & $\mathbf{6 ~ s a}$ \\
\hline Orafütme Hızı & Faz yapısı & Partikül boyutu & Faz yapısı \\
\hline \multirow{2}{*}{ Aktif C } & 350 devir/dk & $\mathrm{B}_{4} \mathrm{C}-\mathrm{C}(\%$ 13-15) & $10-80 \mu \mathrm{m}$ & - \\
& 600 devir/dk & $\mathrm{B}_{4} \mathrm{C}-\mathrm{C}(\% 13-15)$ & $5-50 \mu \mathrm{m}$ & - \\
\hline
\end{tabular}




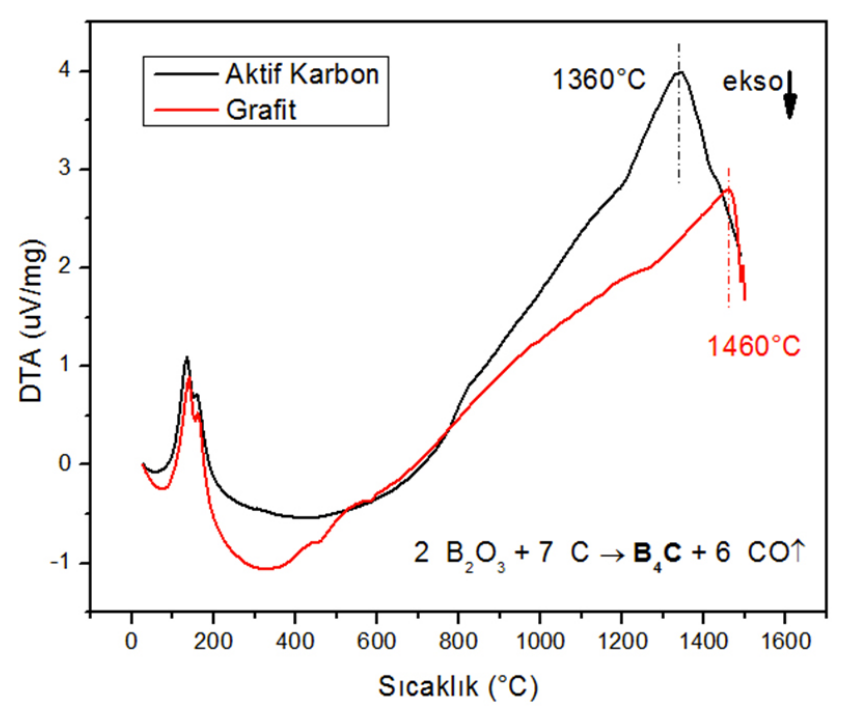

Şekil 13. 3 sa mekanik olarak aktive edilen (350 devir/dk) toz karışımlarının DTA eğrileri: aktif karbon ve grafit kullanımının reaksiyon sıcaklığı üzerindeki etkisi (DTA curves of the powder blends mechanically activated for $3 \mathrm{~h}(350 \mathrm{rpm})$ : The effect of using active carbon or graphite on the reaction temperature).

özellikle düşük partikül boyutlu bor karbür sentezi için büyük önem taşımaktadır.

Şekil 1'deki SEM görüntülerinden, aktif karbonun çok daha kırılgan yüzeyleri olan bir mikro yapıya sahip olduğu görülmektedir. Grafit tozları ise nispeten üst üste binmiş ince katmanlardan oluşmaktadır. Mekanik aktivasyon sayesinde kırılgan yapılardan iyice küçültülmüş ve homojen bir şekilde karıştırılmış başlangıç malzemeleri elde edilmektedir. Literatürdeki bazı çaIsşmalarda da, aktif karbonun diğer karbon kaynaklarına göre daha reaktif olması ve yüzey alanının genişliği sebebi ile $\left(B E T_{P K}=19,7 \mathrm{~m}^{2} / \mathrm{g}, B E T_{A K}=766 \mathrm{~m}^{2} / \mathrm{g}\right.$ ) düşük sıcaklıklarda ve yüksek saflıkta $B_{4} C$ üretimine olanak sağladığı görülmektedir [22-24]. Ayrıca Şekil 1'deki XRD paternlerinden, aktif karbonun grafite göre amorf yapısı açıkça gözlemlenmektedir ve sahip olduğu amorfluğu kimyasal reaktivitesini artırmaktadır. Bor kaynağı olarak, $\mathrm{H}_{3} \mathrm{BO}_{3}$ ve karbon kaynağı olarak petrol koku ve aktif karbonun karşılaştırdığı çalışmalarda, aktif karbon ile gerçekleştirilen sentezlerin, petrol kokuna katalizör ( $\mathrm{NaCl}$ ) eklenmesine rağmen daha yüksek verim ve daha uygun sitokiyometrik oranlarda $\mathrm{B}_{4} \mathrm{C}$ eldesine olanak sağladığı görülmüştür [25]. Bu çalışma kapsamında elde edilen sonuçlar da, literatürdeki sonuçları desteklemektedir.

Sonuç olarak, başlangıç toz karışımları birbiriyle karşılaştırıldığında, en iyi sonuç stokiyometrik $\mathrm{B}_{2} \mathrm{O}_{3}$-aktif C kullanımında elde edilmiştir: 3 sa mekanik olarak aktive edilen (350 devir/dk) ve $1450^{\circ} \mathrm{C}$ 'de tüp fırında reaksiyona giren stokiyometrik $\mathrm{B}_{2} \mathrm{O}_{3}$-aktif $\mathrm{C}$ toz karışımlarına ait tozlar az miktarda kalıntı karbon içeren bor karbür tozlarıdır.

\section{Sonuçların değerlendirilmesi (Conclusions)}

$\mathrm{Bu}$ çalışmada, iki farklı karbon kaynağı kullanılarak elde edilen farklı stokiyometrilerdeki $\mathrm{B}_{2} \mathrm{O}_{3}-\mathrm{C}$ karışımları tüp fırında reaksiyona sokulmuş ve bu parametrelerin son ürün faz oluşumu ve mikroyapı üzerindeki etkisi incelenmiştir. Aynı koşullardaki mekanik aktivasyon ve aynı sıcaklık/süredeki reaksiyon sonrasında, karbon kaynağı olarak aktif karbon kullanımının grafit kullanımı ile karşılaştırıldığında, son üründeki kalıntı karbon miktarını önemli ölçüde azalttığı gözlemlenmiştir. Bunun yanında, her iki durumda stokiyometri fazlası $\mathrm{B}_{2} \mathrm{O}_{3}$ kullanımı, son üründeki kalıntı karbon miktarını azaltırken, yapıda istenmeyen ara fazların oluşumuna neden olmaktadır. 3 sa mekanik olarak aktive edilen (350 devir/dk) stokiyometrik $\mathrm{B}_{2} \mathrm{O}_{3}$-aktif $\mathrm{C}$ toz karışımlarının $1450^{\circ} \mathrm{C}$ 'de tüp fırında reaksiyona girmesi sonucu yapısında \% 4 oranında serbest karbon içeren bor karbür tozları oluşmuştur. Elde edilen tozların partikül boyutunun yaklaşık 5-30 $\mu \mathrm{m}$ aralığında olduğu gözlemlenmiş ve ortalama partikül boyutu $10 \mu \mathrm{m}$ olarak hesaplanmıştır. Bu çalışma neticesinde, $\mathrm{B}_{4} \mathrm{C}$ oluşum sıcaklığının $1360^{\circ} \mathrm{C}$ 'ye kadar düşürülebildiği gösterilmiş olup; elde edilen sonuçlar, düşük partikül boyutlu tozun ihtiyaç olduğu özel uygulamalardaki kullanım için yol gösterici olabilecektir.

\section{Teşekkürler (Acknowledgement)}

Bu çalışma, Koç Üniversitesi Akkim Bor Tabanlı Malzemeler ve İleri Teknoloji Kimyasallar Uygulama ve Araştırma Merkezi (KABAM) laboratuvarlarında Ak-Kim Kimya San. ve Tic. A.Ş. desteği ile gerçekleştirilmiştir.

\section{Kaynaklar (References)}

[1] Thevenot F., Boron carbide-a comprehensive review, J. Eur. Ceram. Soc., 6 (4), 205-225, 1990.

[2] Suri A. K., Subramanian C., Sonber J. K., Murthy T. C., Synthesis and consolidation of boron carbide: A review, Int. Mater. Rev., 55 (1), 4-40, 2010.

[3] Krutskii Y. L., Bannov A. G., Synthesis of boron carbide fine powder using carbon nanofibers. In Strategic Technology (IFOST), 2016 11th International Forum on (pp. 54-57). IEEE, 2016.

[4] Serebryakova T. I., Neronov V. A., Peshev P. D., HighTemperature Borides, Moscow: Metallurgiya, Chelyabinsk Branch, 1991.

[5] Kislyi P. S., Kuzenkova M. A., Bodnaruk N. I., Grabchuk B. L., Boron carbide. Naukova Dumka, Kiev, 216 , 1988.

[6] Kremenchugskii M. V., Savkin G. G., Malinov N. I., Rachkovskii A. I., Smorchkov G. Y., Superlight ceramic armored protected materials synthesized by means of nanostructure mechanoactived boron carbide powders, Nanotechnol. Russ., 3 (3-4), 141-146, 2008.

[7] Yamada S., Hirao K., Yamauchi Y., Kanzaki, S., Mechanical and electrical properties of $\mathrm{B}_{4} \mathrm{C}-\mathrm{CrB}_{2}$ ceramics 
fabricated by liquid phase sintering, Ceram. Int., 29 (3), 299-304, 2003.

[8] Foroughi P., Cheng Z., Understanding the morphological variation in the formation of $\mathrm{B}_{4} \mathrm{C}$ via carbothermal reduction reaction, Ceram. Int., 42 (14), 15189-15198, 2016.

[9] Murray P., Low temperature synthesis of boron carbide using a polymer precursor powder route (Doctoral dissertation, University of Birmingham), 2013.

[10] Benton S. T., Masters, D. R., U.S. Patent No. 3,914,371, Washington, DC: U.S. Patent and Trademark Office, 1975.

[11] Weimer A. W., Roach R. P., Haney C. N., Moore W. G. Rafaniello, W., Rapid carbothermal reduction of boron oxide in a graphite transport reactor. AIChE journal, 37 (5), 759-768, 1991

[12] Weimer A. W., Moore W. G., Roach R. P., Hitt J. E. Dixit R. S., Pratsinis S. E., Kinetics of carbothermal reduction synthesis of boron carbide, J. Am. Ceram. Soc., 75 (9), 2509-2514, 1992.

[13] Foroughi P., Cheng Z., From micron-sized particles to nanoparticles and nanobelts: Structural non-uniformity in the synthesis of boron carbide by carbothermal reduction reaction, Advances in Ceramic Armor XI, 600, 51, 2015.

[14] Hadian A. M., Bigdeloo J. A., The effect of time, temperature and composition on boron carbide synthesis by sol-gel method, J. Mater. Eng. Perform., 17 (1), 44-49, 2008.

[15] Singh P., Singh B., Kumar M., Kumar, A., One step reduction of boric acid to boron carbide nanoparticle, Ceram. Int., 40 (9), 15331-15334, 2014.

[16] Gao S., Li X., Wang S., Xing P., Kong J., Yang G., A low cost, low energy, environmentally friendly process for producing high-purity boron carbide, Ceramics International 45, 3101-3110, 2019.

[17] Sivkov A., Rakhmatullin H., Shanenkov I., Shanenkova
Y., Boron carbide $B_{4} C$ ceramics with enhanced physico-mechanical properties sintered from multimodal powder of plasma dynamic synthesis, Int. J. Refract. Met. Hard Mater, 78, 85-91, 2019.

[18] Vijay S. K., Krishnaprabhu R., Chandramouli V., Anthonysamy S., Synthesis of nanocrystalline boron carbide by sucrose precursor methodoptimization of process conditions, Ceram. Int. 44, 4676-4684, 2018.

[19] Yılmaz D., Koç N., Turan S., Yerli borik asitten kalıntı karbon içermeyen bor karbür sentezi, AKÜ FEMÜBiD 18, 015701, 306-314, 2018.

[20] Sheng Y., Li G., Meng H., Han Y., Xu Y., Wu J., Zhang, $X$., An improved carbothermal process for the synthesis of fine-grained boron carbide microparticles and their photoelectrocatalytic activity, Ceram. Int., 44 (1), 1052-1058, 2018.

[21] Balcı Ö., Ağaoğulları D., Ovalı D., Öveçoğlu M.L., Duman İ., In situ synthesis of $\mathrm{NbB}_{2}-\mathrm{NbC}$ composite powders by milling-assisted carbothermal reduction of oxide raw materials, Adv. Powder Technol. 26, 1200 1209, 2015.

[22] Ahmed S.A.S., El Enin R.M.M.A., El Nabarawy T., Adsorption properties of activated carbon prepared from pre-carbonized petroleum coke in the removal of organic pollutants from aqueous solution, Carbon Letters, 12, (3) 152-161, 2011.

[23] Alizadeh A., Taheri Nassaj E., Ehsani N., Baharvandi H.R., Production of boron carbide powder by carbothermic reduction from boron oxide and petroleum coke or carbon active, Adv. Appl. Ceram., 105 (1), 291-296, 2006.

[24] Cicek B. Karaahmet O., Bor Karbür ve Düşük Sıcaklık Bor Karbür Sentezleme Yöntemleri, Nobel Akademik Yayıncılık, 2018.

[25] Alizadeh A., Taheri, E., Ehsani boron carbide by carbothermic reduction method, J. Eur. Ceram. Soc. 24, (3) 3227-3234, 2004 